\title{
Analysis on the Evolution Path of Promoting the College Students' Entrepreneurship
}

\author{
Tian Yanan ${ }^{1}$ \\ ${ }^{1}$ College of Economics and Management, Nanjing University of Aeronautics and Astronautics, China \\ Correspondence: Tian Yanan, College of Economics and Management, Nanjing University of Aeronautics and \\ Astronautics, China. E-mail: 1031588458@qq.com
}

Received: September 10, 2018

Accepted: September 30, 2018

Online Published: October 12, 2018

doi:10.5539/ijbm.v13n11p102

URL: https://doi.org/10.5539/ijbm.v13n11p102

\begin{abstract}
Promote the deep cooperation between government and university is conducive to promoting the development of college students' entrepreneurship. In order to study how to promote the evolution of college students 'entrepreneurship, this paper uses the theory of evolutionary game to construct the evolutionary game model of political and university collaboration and promote the stability and balance of college students' entrepreneurship. The study draws the relevant phase diagram of the system, and analyzes the influence of the relevant parameters on the evolution mechanism in the process of coordination between government and government.
\end{abstract}

Keywords: college students' entrepreneurship, evolutionary game, government-university cooperation, payment of income model

\section{Introduction}

China's economy has entered the "new normal", the economic structure has been continuously optimized and upgraded. Popular entrepreneurship and innovation have become a new mechanism to promote economic system reform and lead a new path of innovation (Li \& Shan, 2013). Encouraging and supporting college students' entrepreneurship can effectively alleviate employment pressure, stimulate the innovation vitality of the whole society, and provide new growth momentum for adapting to the "new normal". However, the actual entrepreneurship rate of college students has always been low. According to the "Report on the Employment Report of Chinese University Students", the entrepreneurship rate of 2014 graduates is $2.9 \%$, the entrepreneurship rate of 2015 graduates is $3.0 \%$, and the entrepreneurship rate of 2016 graduates is $2.93 \%$, which is still far from the $20 \%-30 \%$ entrepreneurship ratio in Western developed countries (Jin, 2015).

College students' entrepreneurship is an open social system project, involving the interests of multiple social subjects, including college students, government, universities and so on, which are influenced by various aspects and fields. Therefore, support for college students' entrepreneurship cannot only rely on traditional strategic support, but also needs to integrate all kinds of social favorable resources, build an ecosystem throughout the whole process of college students' entrepreneurship support, form synergies among organizations, and maximize synergies to promote college students' entrepreneurship (Liu \& Feng, 2017). In the complex system of college students' entrepreneurship, universities undertake the important function of developing college students' entrepreneurship education and training innovative talents. As the core subject of college students' innovation and entrepreneurship, it bears the key responsibility of coordinating the surrounding entrepreneurial environment, and plays an irreplaceable role in building the entrepreneurial atmosphere and setting up the entrepreneurial practice platform for college students. At the same time, governments at all levels actively responded to the national call and introduced supporting policies and systems for innovation and entrepreneurship, including tax reduction and exemption for enterprises, free provision of places, opening of green financing channels, etc., but all of them have little effect due to weak operability (Liu, 2015). It can be seen that the government and universities have the common responsibility to promote the entrepreneurship of college students, have the interest appeal of deep collaboration, and have more complementary and convenient cooperation. Therefore, based on the evolutionary game model, it is of great theoretical value and practical significance to study the evolutionary mechanism of college students' entrepreneurship jointly promoted by political schools, analyze its balance and stability, and calculate the input and output benefits of both parties. 


\section{Evolutionary Model Construction}

Evolutionary game theory is a theory that combines game theory with dynamic evolution process. Taking participating groups as research objects, it assumes that all participating groups are limited rational and emphasizes the balance of dynamic adjustment, that is, individual behavior is realized through continuous learning, imitation and adjustment, and its core is the stable strategy of evolution (Mei, Ma, \& Du, 2009; Kessler \& Cohrs, 2008; Zhang \& Wang, 2011). The synergy theory was first made by the German physicist hawking in the 1970s, in the field of management, the concept of collaborative often use the expression "1 $+1>2$ ", namely, if each subsystem in the system coordination, cooperation and create synergies, tend to make the system as a whole effect is greater than the sum of each subsystem effect (Jiang \& Zhu, 2015) ${ }^{[8]}$. Synergy is a dynamic process of interdependence and mutual promotion.

The government and universities jointly promote the entrepreneurship of university students, which is not only a simple superposition of the efforts of the government, universities and students themselves, but also through the deep cooperation, integration of resources and effective interaction among various subjects to create a good environment conducive to the entrepreneurship of university students and improve their initiative. However, the cooperation between the government and universities needs to be guided in a proper way. If the government and universities do not truly realize the cooperation in the system, the "1+1>2" effect cannot be achieved, but may produce negative effect with twice the effort.

\subsection{Model Hypothesis}

The main body of the game is the government and the university, the game both have limited rationality, its common goal is to promote college students to start a business. The government strategy space \{coordination, not coordination\}, the university strategy space \{coordination, not cooperate\}. For a clearer description of the relationship between the two parties, make the following assumptions.

(1) Assuming that the government and the university choose not to cooperate, the income of the government and the university is $\mathrm{Rz}, \mathrm{Rg}$. Rz said college students entrepreneurship for government jobs and taxes and social innovation atmosphere build, Rg said college students entrepreneurial success bring universities of intangible assets such as social reputation, entrepreneurial alumni giving back to school and cooperation and so on economic effect, and the university personnel training effect, innovation, entrepreneurship demonstration effect, etc.

(2) Suppose the government and universities choose together, cooperate each side needs to pay a certain cost $\mathrm{Cz}$, $\mathrm{Cg}, \mathrm{Cz}$ said the government and universities cooperation, provide some business infrastructure, entrepreneurship subsidies subsidy and preferential tax breaks and other business services, $\mathrm{Cg}$ said that universities offer entrepreneurial services such as the establishment of entrepreneurship education courses and the construction of entrepreneurship teachers, the construction of innovation and entrepreneurship LABS and incubators, as well as the recommendation of innovative and entrepreneurial talents and the recommendation of scientific research achievements. At the same time, the cooperation between government and universities will bring synergies and obtain extra utility beyond normal benefits. The synergies between government and universities are $\mathrm{Sz}$ and $\mathrm{Sg}$ respectively. Excess benefit Sz refers to providing more perfect services to entrepreneurial teams after collaboration, promoting the entrepreneurship of college students, attracting excellent university innovation and entrepreneurship talents, transforming new technologies into achievements, and promoting the development of local innovative industries. Sg refers to the government's support and preference of policies, funds, public services and other resources to the participating universities, which brings comprehensive benefits to the universities. From the perspective of long-term and overall interests, $\mathrm{Sz}>\mathrm{Cz}, \mathrm{Sz}>\mathrm{Rz}$; And $\mathrm{Sg}>\mathrm{Cg}, \mathrm{Sg}>\mathrm{Rg}$; And $\mathrm{Cz}>\mathrm{Cg}, \mathrm{Sg}>\mathrm{Sz}$.

(3) Assume that when the government chooses to cooperate and the university chooses not to cooperate, the government will pay the cooperative cost $\mathrm{Cz}$, while the university does not pay the cooperative cost, and at the same time, the university will get the benefit $\mathrm{M}$ from the cooperative behavior provided by the government, $\mathrm{M}<\mathrm{Sg}$. The opportunity benefit $\mathrm{M}$ mainly refers to the resources that the university obtains from the supporting resources provided by the government. On the contrary, when universities choose to cooperate and governments choose not to cooperate, universities pay the cost $\mathrm{Cg}$, and the government benefits from cooperative behavior provided by universities $\mathrm{N}, \mathrm{N}<\mathrm{Sz}$. The opportunity income $\mathrm{N}$ of the government mainly refers to the benefit obtained by the transformation of the high-tech achievements of university students. 
Establish a payment matrix between the government and universities based on the above assumptions, as shown in table 1 .

Table 1. The game payment matrix between the government and universities

\begin{tabular}{llll}
\hline & & $\begin{array}{l}\text { Universities } \\
\text { coordination }\end{array}$ & not coordination \\
\hline \multirow{2}{*}{ Government } & coordination & $\mathrm{R}_{\mathrm{z}}+\mathrm{S}_{\mathrm{z}}-\mathrm{C}_{\mathrm{z}}, \mathrm{R}_{\mathrm{g}}+\mathrm{S}_{\mathrm{g}}-\mathrm{C}_{\mathrm{g}}$ & $\mathrm{R}_{\mathrm{z}}-\mathrm{C}_{\mathrm{z}}, \mathrm{R}_{\mathrm{g}}+\mathrm{M}$ \\
& not coordination & $\mathrm{R}_{\mathrm{z}}+\mathrm{N}, \mathrm{R}_{\mathrm{g}}-\mathrm{C}_{\mathrm{g}}$ & $\mathrm{R}_{\mathrm{z}}, \mathrm{R}_{\mathrm{g}}$ \\
\hline
\end{tabular}

\subsection{Evolution of the Model}

Assuming that the probability of government choosing coordination is $p$, the probability of choosing non-synergy is $1-p$, and that of universities is $q$, then the probability of choosing non-synergy is $1-q, 0 \leq p \leq 1$, $0 \leq \mathrm{q} \leq 1$. The expected income of the "coordination" strategy is $\mathrm{U}_{1}$, and the "not coordination" strategy is $\mathrm{U}_{2}$, with the average return of $\overline{\mathrm{U}}$.

$$
\begin{gathered}
\mathrm{U}_{1}=\mathrm{q}\left(\mathrm{R}_{\mathrm{z}}+\mathrm{S}_{\mathrm{z}}-\mathrm{C}_{\mathrm{z}}\right)+(1-\mathrm{q})\left(\mathrm{R}_{\mathrm{z}}-\mathrm{C}_{\mathrm{z}}\right)=\mathrm{qS}_{\mathrm{z}}+\mathrm{R}_{\mathrm{z}}-\mathrm{C}_{\mathrm{z}} \\
\mathrm{U}_{2}=\mathrm{q}\left(\mathrm{R}_{\mathrm{z}}+\mathrm{N}\right)+(1-\mathrm{q}) \mathrm{R}_{\mathrm{z}}=\mathrm{qN}+\mathrm{R}_{\mathrm{z}} \\
\overline{\mathrm{U}}=\mathrm{pU}_{1}+(1-\mathrm{p}) \mathrm{U}_{2}=\mathrm{pqS}_{\mathrm{z}}-\mathrm{pC} \mathrm{C}_{\mathrm{z}}+\mathrm{qN}+\mathrm{R}_{\mathrm{z}}-\mathrm{pqN}
\end{gathered}
$$

In the same way, the expected return of universities choosing " coordination " strategy is $\mathrm{V} 1$, while the expected return of choosing " not coordination " strategy is $\mathrm{V} 2$, and the average return is $\overline{\mathrm{V}}$.

$$
\begin{gathered}
\mathrm{V}_{1}=\mathrm{p}(\mathrm{Rq}+\mathrm{Sq}-\mathrm{Cq})+(1-\mathrm{p})(\mathrm{Rq}-\mathrm{Cq})=\mathrm{pSq}+\mathrm{Rq}-\mathrm{Cq} \\
\mathrm{V}_{2}=\mathrm{p}\left(\mathrm{R}_{\mathrm{q}}+\mathrm{M}\right)+(1-\mathrm{p}) \mathrm{R}_{\mathrm{q}}=\mathrm{pM}+\mathrm{R}_{\mathrm{q}} \\
\overline{\mathrm{V}}=\mathrm{qV}_{1}+(1-\mathrm{q}) \mathrm{V}_{2}=\mathrm{pqS}_{\mathrm{q}}-\mathrm{qC}_{\mathrm{q}}+\mathrm{pM}+\mathrm{R}_{\mathrm{q}}-\mathrm{pqM}
\end{gathered}
$$

According to the malthusian dynamic equation, the growth rate of the strategy is equal to its corresponding fitness (Friedmand, 1991), and the dynamic equation (7) of the strategic communication between the government and universities evolved over time is obtained.

$$
\left\{\begin{array}{l}
F=\frac{d p}{d t}=p\left(U_{1}-\bar{U}\right)=p(1-p)\left(q S_{z}-q N-C_{z}\right) \\
G=\frac{d q}{d t}=q\left(V_{1}-\bar{V}\right)=q(1-q)\left(p S_{q}-p M-C_{q}\right)
\end{array}\right.
$$

According to the method proposed by Firedman, the stability of the equilibrium point of an evolutionary system can be obtained by the local stability analysis of Jaconbian matrix of the system (Cui \& Wei, 2014; Guan, Zhang \& Liu, 2016; Yin, Chen \& Yang, 2016). Let the corresponding Jacobian of equation (7) be J.

$$
J=\left(\begin{array}{cc}
(1-2 p)\left(q S_{z}-q N-C_{z}\right) & p(1-p)\left(S_{z}-N\right) \\
q(1-q)\left(S_{q}-M\right) & (1-2 q)\left(\mathrm{pS}_{\mathrm{q}}-\mathrm{pM}-\mathrm{C}_{\mathrm{q}}\right)
\end{array}\right)
$$

\section{Model Analysis}

\subsection{Equilibrium Points and Stability Analysis}

Evolutionary stability strategy refers to that the bounded rational subject adjusts the behavioral strategy to gain more utility in the process of game, and finally forms a dynamic balance (Dong, Du, \& Ren, 2013). According to the definition of the evolutionary stability strategy (ESS), the stable state has stability, that is, the stable state $x$ needs to satisfy $\mathrm{F}(\mathrm{x})=0$ and $\mathrm{F}^{\prime}(\mathrm{x})<0$. According to the above replication dynamic equation, when $\mathrm{p}=0$ or 1 or $\mathrm{q}=\mathrm{Cz} /(\mathrm{Sz}-\mathrm{N})$, the proportion of "coordinated" strategy adopted by the government is stable. When $\mathrm{q}=0$ or 1 or $\mathrm{p}=\mathrm{Cq} /(\mathrm{Sq}-\mathrm{M})$, the proportion of colleges and universities adopting "coordination" strategy is stable. Because $0 \leq \mathrm{p} \leq 1, \quad 0 \leq \mathrm{q} \leq 1$, so $\mathrm{Cq} \leq \mathrm{Sq}-\mathrm{M}, \mathrm{C}_{\mathrm{z}} \leq \mathrm{S}_{\mathrm{z}}-\mathrm{N}$. Under this constraint, the local stability of the five equilibrium points is judged by the jacobian matrix, as shown in table 2 . 
Table 2. Analysis of equilibrium local stability

\begin{tabular}{lcl}
\hline Equilibrium point & Determinant of J & $\begin{array}{l}\text { Local } \\
\text { stability }\end{array}$ \\
\hline$(0,0)$ & $\mathrm{C}_{\mathrm{z}} \mathrm{C}_{\mathrm{g}}$ & ESS \\
$(0,1)$ & $\mathrm{C}_{\mathrm{g}}\left(\mathrm{S}_{\mathrm{z}}-\mathrm{N}-\mathrm{C}_{\mathrm{z}}\right)$ & Unstable \\
$(1,0)$ & $C_{\mathrm{z}}\left(S_{g}-M-C_{g}\right)$ & Unstable \\
$(1,1)$ & $\left(\mathrm{S}_{\mathrm{g}}-\mathrm{M}-\mathrm{C}_{\mathrm{g}}\right)\left(\mathrm{S}_{\mathrm{z}}-\mathrm{N}-\mathrm{C}_{\mathrm{z}}\right)$ & ESS \\
$\left(\frac{\mathrm{C}_{\mathrm{q}}}{\mathrm{S}_{\mathrm{q}}-\mathrm{M}}, \frac{\mathrm{C}_{\mathrm{z}}}{\mathrm{S}_{\mathrm{z}} \mathrm{N}}\right)$ & $\frac{-\mathrm{C}_{\mathrm{z}} \mathrm{C}_{\mathrm{g}}\left(\mathrm{S}_{\mathrm{g}}-\mathrm{M}-\mathrm{C}_{\mathrm{g}}\right)\left(\mathrm{S}_{\mathrm{z}}-\mathrm{N}-\mathrm{C}_{\mathrm{z}}\right)}{\left(\mathrm{S}_{\mathrm{g}}-\mathrm{M}\right)\left(\mathrm{S}_{\mathrm{z}}-\mathrm{N}\right)}$ & Saddle point \\
\hline
\end{tabular}

According to the local stability analysis, $(0,1)$ and $(1,0)$ are both unstable points, and $(0,0)$ and $(1,1)$ are stable equilibrium points, which clearly represent two situations: the government adopts the cooperative strategy, and the universities also adopts the cooperative strategy. Neither the government nor the universities are in sync.

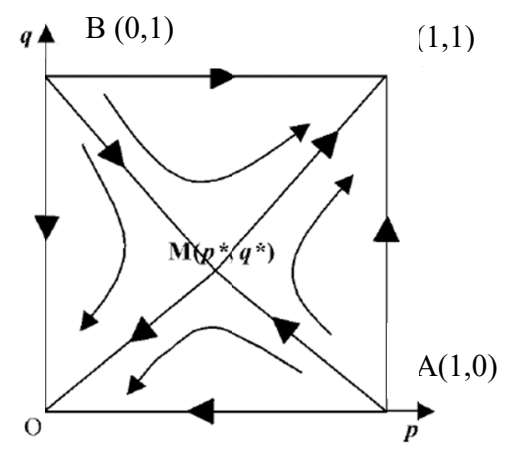

Figure 1. Dynamic process of collaboration between government and universities

$\left(\frac{\mathrm{Cq}}{\mathrm{Sq}-\mathrm{M}}, \frac{\mathrm{Cz}}{\mathrm{Sz}-\mathrm{N}}\right)$ is the saddle point, and the connection between the saddle point and the two non-equilibrium points is the boundary line where the game converges to different modes. The right region of the broken line represents the probability of convergence to the ideal state, while the left region represents the probability of convergence to the bad state, as shown in figure 1 . It can be seen from the expression of saddle point that the evolution game can be adjusted to make it evolve toward the ideal state and realize synergistic effect by adjusting the related parameters of synergy.

\subsection{System Phase Diagram and Parameter Analysis}

Based on the above model and analysis, this paper analyzes the effects of the cost of collaboration, synergistic effect and the extra benefits obtained when one party chooses not to cooperate with the other party on the evolution results, and draws the corresponding phase diagram.

(1)The influence of $\mathrm{Cz}$ on evolution results. According to the saddle point expression, the higher the collaborative cost paid by the government, the vertical upward movement of the saddle point makes the area of the quadrilateral $\mathrm{S}_{\mathrm{AMBC}}$ decrease and the probability of convergence to the ideal state (coordination, coordination) decreases, which is not conducive to the good evolution of the system, as shown in figure 2 . On the contrary, the lower the cost of coordination paid by the government, the saddle point moves down and the probability of convergence to the ideal state increases. The higher the cost of coordination paid by the government, the vertical upward movement of saddle point makes the area of quadrilateral SAMBC decrease and the probability of convergence to the ideal state (coordination, coordination) decreases, which is not conducive to the good evolution of the system, as shown in figure 2. On the contrary, the lower the cost of coordination paid by the government, the saddle point moves down and the probability of convergence to the ideal state increases 


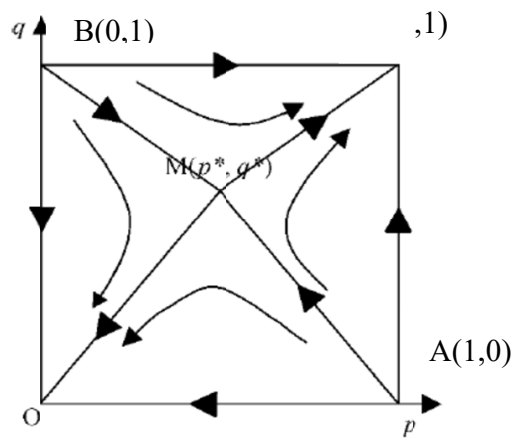

Figure 2. Increase of parameter $C_{z}$

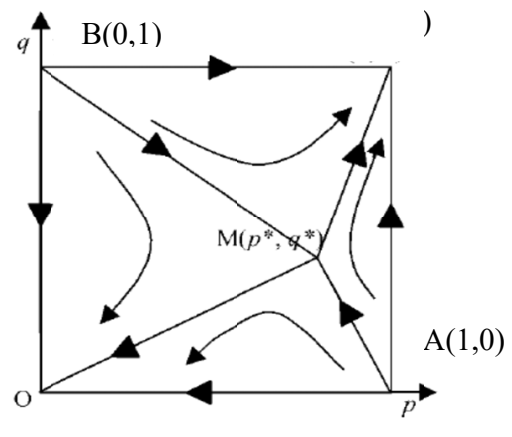

Figure 3. Increase of parameter $C_{g}$

(2) The influence of $\mathrm{Cg}$ on evolution results. When $\mathrm{Cg}$ increases, the saddle point moves to the right in the horizontal direction, making the area of quadrilateral $\mathrm{S}_{\mathrm{AMBC}}$ decrease and the probability of the system convergence to the bad state increase, as shown in figure 3 . The result shows that the higher the cost of cooperation is, the worse the system evolves.

(3) The effect of the extra utility $S_{z}$ obtained by the government on the evolution results. .According to the saddle point expression, the higher the additional $\mathrm{S}_{\mathrm{z}}$ obtained by the government through cooperation, the vertical downward movement of the saddle point, and the probability of convergence to the ideal state is increased, as shown in figure 4. The government should cooperate with universities to promote the entrepreneurship of college students, provide more jobs, and promote the development of innovation and entrepreneurship. The higher the government's synergies, the system will evolve towards the ideal state.

(4) The effect of the extra utility Sg obtained by universities on the evolution results. The saddle point moves horizontally to the left along with the increase of the extra income obtained by the university, which increases the probability that the system converges to the ideal state, as shown in figure 5.

(5) The impact of opportunity return $\mathrm{M}$ and $\mathrm{N}$ on the evolution results, as above, is not analyzed in detail. When only one side chooses to cooperate and the other side chooses not to cooperate, and the greater the opportunity benefit of the non-cooperative side, the more unfavorable it is for the system to evolve to the ideal state. Only when $\mathrm{M}$ and $\mathrm{N}$ tend to grow together between the government and universities, the possibility of collaboration between the two parties is greater, and both parties obtain equal benefits, which is conducive to the evolution of the system towards deep synergy.

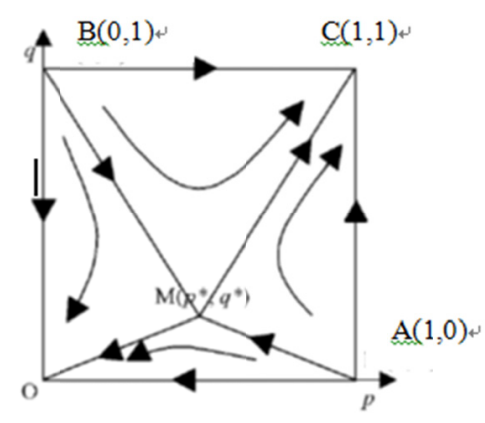

Figure 4. Increase of parameter $S_{z}$

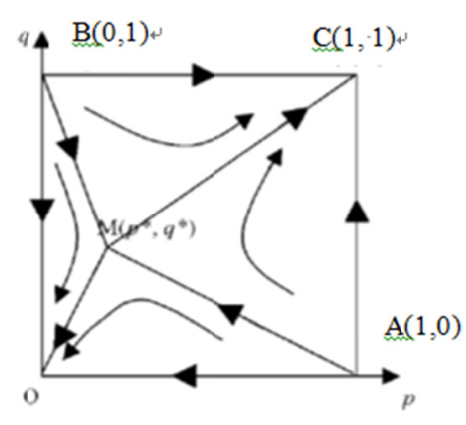

Figure 5. Increase of parameter $S_{g}$

To sum up, the change of related parameters will affect the probability that the system converges to different states, as shown in the table below. 
Table 3. Influence of parameter variation on saddle point

\begin{tabular}{lll}
\hline Parameters change & $\begin{array}{l}\text { The direction of } \\
\text { the saddle point }\end{array}$ & $\begin{array}{l}\text { Convergence to } \\
\text { the ideal state } \\
\text { probability }\end{array}$ \\
\hline $\mathrm{C}_{\mathrm{z}}$ increase, $\mathrm{S}_{\mathrm{z}}$ decrease, $\mathrm{N}$ increase & move up & decrease \\
$\mathrm{C}_{\mathrm{z}}$ decrease, $\mathrm{S}_{\mathrm{z}}$ increase, $\mathrm{N}$ decrease & move down & $\begin{array}{l}\text { increase } \\
\mathrm{C}_{\mathrm{g}} \text { increase, } \mathrm{S}_{\mathrm{g}} \text { decrease, } \mathrm{M} \text { increase }\end{array}$ \\
$\mathrm{C}_{\mathrm{g}}$ decrease, $\mathrm{S}_{\mathrm{g}}$ increase, $\mathrm{M}$ decrease & move right & $\begin{array}{l}\text { decrease } \\
\text { move left }\end{array}$ \\
\hline
\end{tabular}

\section{Conclusion and Suggestion}

To promote the entrepreneurship of college students and improve their entrepreneurship rate and success rate, the government and universities need to cooperate and interact, share high-quality start-up resources and explore deep entrepreneurial opportunities, which has become an important model to promote the systematic evolution of entrepreneurship growth of college students. Based on the theory of evolutionary game, this paper explores and analyzes the problem of promoting the entrepreneurship of college students, and finds that the evolution system converges to two states: the bad state where the government chooses not to cooperate and the university chooses not to cooperate, and the ideal state where the government and the university choose to cooperate, both of which are the evolutionary stability strategies (ESS). According to system phase diagram 2, 3, 4, 5 and table 3 , it can be seen that adjusting the values of relevant parameters, such as reducing the collaborative cost between the government and universities, increasing the excess benefits of cooperation, and reducing the opportunity benefits obtained by the government and universities, can expand the area of quadrangle $\mathrm{S}_{\mathrm{AMBC}}$ and promote the evolution of the system towards the ideal state. Therefore, in view of the main problems of college students' entrepreneurship in reality, this paper puts forward some suggestions on how to promote college students' entrepreneurship through the cooperation between government and universities and from the aspects of reducing the cost of cooperation and improving the excess earnings..

(1) Strengthen the policy coordination, reduce the cost of coordination. Scientific and reasonable policy is conducive to promote entrepreneurial activities, stimulate the enthusiasm of college students to start their own businesses, and improve the utilization of resources. The government should fully recognize the important role of university students' entrepreneurship in promoting employment, encouraging innovation and promoting economic development. The government provides policy support in such aspects as start up education training, incubation base (strengthening infrastructure construction), industrial and commercial tax (tax preference, burden reduction), entry threshold (relaxing start-up access conditions, simplifying approval procedures), and follow-up start up services (start up subsidy). At the same time, the government should pay attention to the supporting role of universities in helping and supporting students to start their own businesses. The entrepreneurship education and entrepreneurship competition carried out by colleges and universities can guide students to start their own businesses in the aspects of entrepreneurship opportunity recognition, market risk warning and investment and financing selection. The government should give some preferential policies to the universities that support college students' entrepreneurship, encourage the government and universities to cooperate, reduce the cost of collaboration, improve the efficiency of collaboration, and jointly promote the entrepreneurship of college students. Universities should also formulate supporting policies on campus to encourage the development of entrepreneurial education courses, the establishment and development of entrepreneurial teams, and the construction of entrepreneurial teachers. We should formulate and improve the daily operation and management mechanism, encourage the government and universities to share quality start-up resources, and lead college students to start their own businesses with mutually beneficial entrepreneurship policies, so as to promote the smooth development of entrepreneurial activities and achieve win-win cooperation.

(2) Promote practical collaboration and improve synergies. Entrepreneurial practice is the foundation of entrepreneurial success, and a good entrepreneurial practice environment is the prerequisite guarantee, which can greatly promote the transformation of entrepreneurial achievements. The government leads and cooperates with relevant universities to establish the college students' entrepreneurial practice alliance, and creates a good platform for college students' entrepreneurial practice with the help of social resources and market forces. For example, the entrepreneurial teams are encouraged to visit and learn in leading enterprises of various industries and learn about the relevant processes of internal enterprise operation, so as to make entrepreneurial education gradually go deep into the specific practice and avoid armchair and unrealistic dreams. Besides, relevant government departments and universities should work together to promote the effective connection between 
various business incubators and enterprise incubation bases and provide more practical incubation services. What's more, the government, through the entrepreneurship guidance service center, works with relevant universities to set up excellent entrepreneurship models and practice pioneers, and encourages the fledgling student entrepreneurs with their own experience and experience to give them spiritual inspiration. Last but not the least, the government cooperates with financial investment institutions to open up financing channels for college students' entrepreneurship and provide financial support. Through the cooperation of government and universities, the university entrepreneurs have a more comprehensive and profound understanding of the current situation and future development trend of the external market and the management experience of modern enterprises, so as to improve their entrepreneurial ability and form a "hematopoiesis" support model. Thus, the cooperative cost can be reduced, and the "blood supply" support mode will get rid of the dilemma of high cost and little effect, stimulate the internal vitality, and promote the rapid growth of university students' entrepreneurial enterprises.

However, the entrepreneurial process of college students is not only influenced by the government and universities, but also influenced by other social factors such as enterprises and families. In addition to cooperating with universities, the government should integrate all kinds of social favorable resources and build an entrepreneurial ecosystem. Government should build an ecosystem throughout the whole process of entrepreneurial support for college students, smooth the flow and transmission of materials and information throughout the process, improve the environment for college students to start their own businesses, and motivate their entrepreneurial behaviors, so as to improve the quantity and quality of their start-ups. In addition, the effect of the related parameters involved in constructing the evolutionary game model on the actual evolution mechanism needs further empirical research, which needs to be further improved.

\section{References}

Cui, X. M., \& Wei, Z. (2014). Study on the Game between Green Consumption and Green Entrepreneurship Evolution. Scientific and Technological Progress and Countermeasures, 4(31), 16-20.

Dong, W. B., Du, J. G., Ren, J. (2013). An Evolutionary Game Based Study on Migrant Workers Returning Home to Start their own Businesses. Journal of South China Agricultural University (social science edition), 12(2), 58-63.

Friedmand. (1991). Evolutionary Games in Economics. Economy, 3(59), 637-666. https://doi.org/10.2307/2938222

Guan, X., Zhang, G. X., Liu, D. Y. (2016). The Behavior of Consumer Buying New Energy Vehicles Based on Stochastic Evolutionary Game. Filomat, 15(30), 3987-3999.

Jiang, K. D., \& Zhu, J. Q. (2015). A Study on College Entrepreneurship Collaboration Mechanism. China higher education research, 1, 54-58. https:// doi.org/10.16298/j.cnki.1004-3667.2015.01.10

Jin, B. H. (2015). Research on Development Strategy of College Students' Entrepreneurship Incubator Park. Scientific and Technological Progress and Countermeasures, 32(3), 11-15. https://doi.org/10.6949/kjjbydc.2014060360

Kessler, T., \& Cohrs, J. C. (2008). The Evolution of Authoritarian Process: Fostering Currency in Large - Scale Groups. Journal of Group Dynamics, 1(12), 73-84. https:// doi.org/10.1037/1089-2699.12.1.73

Li, C., \& Biaoan, S. (2013). Entrepreneurship Research in the Context of China: Review and Prospect. Management World, 12, 160-169.

Liu, S. H., \& Feng, J. (2017). Research on College Collaborative Mechanism Construction Oriented by College Students' Entrepreneurship, Chinese adult education, 4, 48-50.

Liu, Z. W. (2015). Reflections on University Students' Entrepreneurship Policies: Policy Deconstruction and Transformation -- Analysis Dimension Based on input-process-output. Education Development Research, 35(17), 62-67. https://doi.org/10.14121/j.cnki. 1008-3855.2015.17.013

Mei, Q., Ma, G. J., \& Du, J. G. (2009). Study on the Evolution of Credit Guarantee Mechanism in Middle and Small Universities. Journal of Systems Engineering, 3(24), 280-285.

Yin, H., Chen, J., Yang, X. C. (2016). Evolutionary Game Analysis of Cooperation between Research and Entrepreneurial Universities in Emerging Industries. Science and Technology Management Research, $36(13), 78-859$. 
Zhang, S. R., Wang, W. P. (2011). Game Analysis of College Cooperative Evolution Based on Knowledge Update. Soft science, 1(25), 24-27.

\section{Copyrights}

Copyright for this article is retained by the author(s), with first publication rights granted to the journal.

This is an open-access article distributed under the terms and conditions of the Creative Commons Attribution license (http://creativecommons.org/licenses/by/4.0/). 